\title{
Visceral Fat Is a Strong Predictor of Insulin Resistance Regardless of Cardiorespiratory Fitness in Non-Diabetic People
}

\author{
Chiyoko Usui ${ }^{1}$, Meiko AsAKA ${ }^{2}$, Hiroshi KAWANO ${ }^{3}$, Tomoko Aoyama ${ }^{3}$, \\ Toshimichi IsHIJIMA ${ }^{2}$, Shizuo SAKAMOTO ${ }^{3}$ and Mitsuru HiguCHI ${ }^{1,3}$ \\ ${ }^{1}$ Consolidated Research Institute for Advanced Science and Medical Care, Waseda University, \\ 513 Wasedatsurumaki, Shinjuku-ku, Tokyo 162-0041, Japan \\ ${ }^{2}$ Graduate School of Sport Sciences, and ${ }^{3}$ Faculty of Sport Sciences, Waseda University, \\ 2-579-15 Mikajima, Tokorozawa, Saitama 359-1192, Japan
}

(Received September 3, 2009)

\begin{abstract}
Summary Abdominal adiposity and low cardiorespiratory fitness are assosicated with insulin resistance in people with impaired glucose tolerance and type 2 diabetes. However, little is known about which factor precedes insulin resistance in people with impaired glucose tolerance and type 2 diabetes, and which is the stronger predictor of insulin resistance in non-diabetic people. The purpose of this study was to examine the relationship between insulin resistance and cardiorespiratory fitness, visceral fat, and subcutaneous fat in nondiabetic people. Subjects included 87 men and 77 women aged 30-72 y (mean \pm SD, $51.3 \pm 12.3 \mathrm{y})$. Cardiorespiratory fitness was assessed by measuring the maximal oxygen uptake $\left(\dot{\mathrm{V}}_{2 \text { max }}\right)$ in a progressive continuous test to exhaustion on a cycle ergometer. The visceral and subcutaneous fat areas were measured by magnetic resonance imaging. The homeostasis model assessment of insulin resistance (HOMA-R) was calculated from the fasting concentrations of glucose and insulin. Stepwise multiple linear regression analysis revealed that visceral and subcutaneous fat were significant correlates of HOMA-R, explaining $24 \%$ and $6 \%$ of the variance, respectively, whereas sex, age, and $\dot{V} \mathrm{O}_{2 \max }$ were not significant independent determinants. Abdominal fat deposition rather than cardiorespiratory fitness is a significant predictor of insulin resistance in non-diabetic people; visceral fat is the most important factor.
\end{abstract}

Key Words insulin resistance, visceral fat, subcutaneous fat, cardiorespiratory fitness, non-diabetic people

In recent years, the frequency of impaired glucose tolerance (IGT) and type 2 diabetes has been increasing dramatically in Japan because of changes in lifestyle toward physical inactivity and a high-fat diet. According to the Outline of the National Health and Nutrition Survey, Japan 2007 (Health Service Bureau, Ministry of Health, Labour and Welfare), about 8.9 million people are strongly suspected of having diabetes, and this number increases to about 22.1 million when those diagnosed with diabetes are included. Furthermore, some epidemiologic studies of type 2 diabetes have shown that the mean body mass index in Japanese type 2 diabetes patients was 23 to $25 \mathrm{~kg} / \mathrm{m}^{2}$ (1-4). This finding suggests that Japanese people, even non-obese individuals, are more susceptible to type 2 diabetes. Therefore, in addition to finding ways to treat or cure the diabetic conditions, it is also essential to develop effective strategies for primary prevention of this metabolic abnormality.

Insulin resistance is an early and key defect of type 2 diabetes (5). A recent study has shown that both abdominal adiposity and cardiorespiratory fitness (CRF) are significant predictors of insulin resistance in older

E-mail: chiyoko@suou.waseda.jp people, including those with prediabetes and diabetes (6). In addition, Nagano et al. (7) investigated the independent contribution of abdominal fat accumulation and low CRF to metabolic abnormalities in patients with IGT and type 2 diabetes, and found that CRF might be one of the predictors of hyperinsulinemia independent of visceral fat (VF) accumulation. However, in the study by Nagano et al. (7), 2 to 24 mo had passed from the time when the elevated glucose concentration was noted. Because patients with IGT and type 2 diabetes generally become less active and exercise intolerant, it is unclear from these data whether metabolic abnormalities such as IGT and insulin resistance precede physical inactivity and low CRF or vice versa. To elucidate the predictors of insulin resistance, it is important to examine the relationship between insulin resistance, CRF, and abdominal fat in all non-diabetic adults and not just in those with IGT or diabetes.

In this context, we evaluated the relative contributions of low CRF and the accumulation of abdominal fat (both VF and subcutaneous fat (SF)) to insulin resistance in non-diabetic people.

\section{MATERIALS AND METHODS}

Subjects. One hundred sixty-four non-diabetic Japa- 
nese people aged 30 to $72 \mathrm{y}$ (mean \pm SD, age: $51.3 \pm$ $12.3 \mathrm{y}$ ) were recruited. This included 77 women (3039 year: $n=17,40-49 \mathrm{y}: n=15,50-59 \mathrm{y}: n=23,60-$ $69 \mathrm{y}: n=22)$ and 87 men $(30-39 \mathrm{y}: n=20,40-49 \mathrm{y}:$ $n=22,50-59 \mathrm{y}: n=16,60-69 \mathrm{y}: n=26,70-\mathrm{y}: n=3)$. No participant had taken medication or had any intervention for diabetes mellitus. The subjects were divided into four groups according to sex and maximal oxygen uptake $\left(\dot{\mathrm{V}} \mathrm{O}_{2 \max }\right)$ reference values, which have been established in the Exercise and Physical Activity Reference Quantity for Health Promotion 2006 (EPARQ2006) (8). All subjects were informed of the purpose and possible risks of the study, and then provided written informed consent. The study was approved by the Ethical Committee at Waseda University.

Body composition analysis. Anthropometric measurements: Body weight (BW) and percentage of body fat (\% body fat) were measured using an electronic scale (Inner Scan BC-600, TANITA Co., Japan), and height was measured by using a stadiometer (YL-65, YAGAMI Inc., Japan). BW, \% body fat and height were measured with subjects wearing light clothing and no shoes. Body mass index (BMI), fat-free mass (FFM), and fat mass (FM) were calculated. Waist circumference (WC) was measured at the umbilical region using a nonelastic measuring tape.

Magnetic resonance imaging (MRI): VF and SF areas were measured by magnetic resonance imaging (MRI; Signa 1.5T, General Electric Co., Milwaukee, Wisconsin, USA). The imaging condition included a T-1 weighted spin-echo and axial-plane sequence with a slice thickness of $10 \mathrm{~mm}$, a repetition time of $140 \mathrm{~ms}$, and an echo time of $12.3 \mathrm{~ms}$. Cross-sectional images were scanned at the umbilical region. During the scan, the subjects were asked to hold their breath for about $30 \mathrm{~s}$ after an inhalation to reduce the respiratory motion artifact. The magnetic resonance images were transferred to a personal computer in Digital Imaging and Communications in Medicine (DICOM) file format, and the cross-sectional areas of the VF and SF at the umbilical region were measured using image-analysis software (Slice-o-matic 4.3 for Windows, Tomovision, Montreal, Canada). Abdominal fat (AF) area was defined as the sum of VF and SF. To minimize interobserver variation, all scans and analyses were performed by the same investigator, and the coefficient of variation was $0.4 \%$ for the cross-sectional areas at the umbilical region.

Measurement of cardiorespiratory fitness (CRF). We assessed maximal oxygen uptake $\left(\dot{V}_{O_{2 m a x}}\right)$, which is defined as the greatest oxygen uptake measured during graded exercise, using a progressive continuous test to exhaustion on a Monark cycle ergometer (Model 828E, Monark Exercise AB, Varberg, Sweden). Subjects performed a 5-min warm-up at a heart rate of 110$120 \mathrm{beats} / \mathrm{min}$, after which the work rate was increased by $15 \mathrm{~W} / \mathrm{min}$ until the subject was unable to maintain the required pedaling frequency of $60 \mathrm{rpm}$. Oxygen consumption and carbon dioxide production were measured using a portable metabolic testing system VO2000 (Medical Graphics Co., USA). The highest value of oxygen consumption during the exercise test was designated as $\dot{\mathrm{V}} \mathrm{O}_{2 \max }$.

$\dot{V} \mathrm{O}_{2 \max }$ reference values. The Japanese Ministry of Health, Labour, and Welfare proposed $\dot{V} \mathrm{O}_{2 \max }$ reference values to prevent lifestyle-related diseases for each age group and for both men and women in Japan (8). The procedure to determine $\dot{\mathrm{V}} \mathrm{O}_{2 \max }$ reference values was described in EPARQ2006 (8). In brief, these $\dot{\mathrm{V}} \mathrm{O}_{2 \max }$ reference values were determined by experts through a systematic review of literature, which showed the threshold values of the $\dot{\mathrm{V}} \mathrm{O}_{2 \text { max }}$ or $\dot{\mathrm{V}} \mathrm{O}_{2 \text { peak }}$, at which the morbidity of lifestyle-related diseases increases statistically in each age group for men and women. The average values of these thresholds for each age group for men and women were then calculated and designated as the $\dot{\mathrm{V}} \mathrm{O}_{2 \max }$ reference values for preventing lifestylerelated diseases. The identified $\dot{V}_{O_{2 m a x}}$ reference values, in $\mathrm{mL} / \mathrm{kg} \mathrm{BW} / \mathrm{min}$, were 32 (30-39 y), 31 (40-49 y), $29(50-59 \mathrm{y})$, and $28(60-69 \mathrm{y})$ for women, and 38 $(30-39 y), 37(40-49 y), 34(50-59 y)$, and 33 (60$69 \mathrm{y})$ for men.

Blood samples. Fasting venous blood samples were collected after a fast of $12 \mathrm{~h}$ or more, and the concentrations of glucose, insulin, and plasma adiponectin, and glycosylated hemoglobin $\left(\mathrm{HbA}_{1 \mathrm{c}}\right)$ level were measured. Serum and plasma samples were stored at $-80^{\circ} \mathrm{C}$ until subsequent analysis. All blood parameters were analyzed by SRL, Inc. (Tokyo, Japan) and Mitsubishi Chemical Medience Corporation (Tokyo, Japan). The homeostasis model assessment of insulin resistance (HOMA-R) was calculated from the fasting concentrations of serum glucose and insulin as follows:

HOMA-R $=($ fasting glucose $(\mathrm{mg} / \mathrm{dL})) \times($ fasting insu$\operatorname{lin}(\mu \mathrm{U} / \mathrm{mL})) / 405$.

Statistical analysis. The data are presented as the mean \pm SD. Statistical analyses were performed using Sigma Stat 2.03 (Systat Software Inc., CA, USA). Statistical analysis was performed using Student's $t$ test for parametric variables and the Mann-Whitney rank-sum test for nonparametric variables to determine differences between women and men. A two-way ANOVA was used to test for interaction effects between sex and CRF for the four groups. Where appropriate, the Tukey test was used to locate the source of the significant differences. Stepwise multiple linear regression analysis was used to analyze the relationships between HOMA-R and sex, age, measures of adiposity (i.e., VF and SF), and $\mathrm{CRF}\left(\dot{\mathrm{V}}_{2 \mathrm{max}}\right)$. For all statistical analyses, the level of significance was defined as less than 0.05.

\section{RESULTS}

The characteristics of all non-diabetic subjects included in the study are shown in Table 1. WC, AF, and VF were significantly higher in men, but SF did not differ significantly between sexes. $\dot{\mathrm{V}} \mathrm{O}_{2 \max }$ expressed as $\mathrm{mL} /$ $\mathrm{kg} \mathrm{BW/min} \mathrm{was} \mathrm{significantly} \mathrm{higher} \mathrm{in} \mathrm{men} \mathrm{but} \mathrm{did} \mathrm{not}$ differ when expressed relative to FFM (mL/kg FFM/ min). HOMA-R did not differ between men and women. Plasma adiponectin concentration was significantly lower in men. 
Table 1. Subject characteristics and metabolic parameters for all subjects.

\begin{tabular}{|c|c|c|c|}
\hline & $\begin{array}{l}\text { Women } \\
(n=77)\end{array}$ & $\begin{array}{c}\text { Men } \\
(n=87)\end{array}$ & $\begin{array}{c}\text { All } \\
(n=164)\end{array}$ \\
\hline Age (y) & $51.7 \pm 12.1$ & $51.1 \pm 12.6$ & $51.3 \pm 12.3$ \\
\hline BW (kg) & $54.8 \pm 8.0$ & $71.8 \pm 10.2^{*}$ & $63.9 \pm 12.5$ \\
\hline BMI $\left(\mathrm{kg} / \mathrm{m}^{2}\right)$ & $22.2 \pm 3.1$ & $24.7 \pm 3.0^{\dagger}$ & $23.6 \pm 3.3$ \\
\hline FM (kg) & $16.9 \pm 5.4$ & $16.4 \pm 5.4$ & $16.7 \pm 5.4$ \\
\hline FFM (kg) & $37.9 \pm 3.7$ & $55.4 \pm 5.7^{\dagger}$ & $47.2 \pm 10.0$ \\
\hline $\mathrm{WC}(\mathrm{cm})$ & $79.3 \pm 9.6$ & $87.2 \pm 7.6^{\dagger}$ & $83.5 \pm 9.4$ \\
\hline $\mathrm{AF}\left(\mathrm{cm}^{2}\right)$ & $218 \pm 98$ & $264 \pm 96^{\dagger}$ & $242 \pm 99$ \\
\hline $\mathrm{VF}\left(\mathrm{cm}^{2}\right)$ & $67 \pm 38$ & $117 \pm 45^{\dagger}$ & $94 \pm 49$ \\
\hline $\mathrm{SF}\left(\mathrm{cm}^{2}\right)$ & $151 \pm 69$ & $147 \pm 65$ & $149 \pm 67$ \\
\hline$\dot{\mathrm{V}} \mathrm{O}_{2 \max }(\mathrm{mL} / \mathrm{kg} \mathrm{BW} / \mathrm{min})$ & $28.8 \pm 5.4$ & $32.7 \pm 6.5^{*}$ & $30.9 \pm 6.3$ \\
\hline$(\mathrm{mL} / \mathrm{kg} \mathrm{FFM} / \mathrm{min})$ & $41.4 \pm 7.1$ & $42.0 \pm 7.4$ & $41.7 \pm 7.3$ \\
\hline Fasting glucose (mg/dL) & $93 \pm 10$ & $98 \pm 15^{\ddagger}$ & $95 \pm 13$ \\
\hline $\mathrm{HbA}_{1 \mathrm{c}}(\%)$ & $5.14 \pm 0.34$ & $5.08 \pm 0.68^{\S}$ & $5.11 \pm 0.55$ \\
\hline Fasting insulin $(\mu \mathrm{U} / \mathrm{mL})$ & $6.10 \pm 2.77$ & $6.62 \pm 3.68$ & $6.38 \pm 3.28$ \\
\hline HOMA-R & $1.41 \pm 0.69$ & $1.60 \pm 0.90$ & $1.51 \pm 0.81$ \\
\hline Adiponectin $(\mu \mathrm{g} / \mathrm{mL})$ & $11.8 \pm 5.0$ & $8.0 \pm 3.9^{\dagger}$ & $9.8 \pm 4.9$ \\
\hline
\end{tabular}

Values are means \pm SD. BW: body weight, BMI: body mass index, FM: fat mass, FFM: fat-free mass, WC: waist circumference, $\mathrm{AF}$ : abdominal fat area $(\mathrm{AF}=\mathrm{VF}+\mathrm{SF}), \mathrm{VF}$ : visceral fat area, SF: subcutaneous fat area, $\mathrm{Hb}_{1 \mathrm{c}}$ : glycosylated hemoglobin, HOMA-R: homeostasis model assessment of insulin resistance $=($ fasting glucose $) \times($ fasting insulin $) / 405 .{ }^{*} p<0.001$ vs. women (Student’s $t$-test), ${ }^{\dagger} p<0.001,{ }^{\ddagger} p<0.01,{ }^{\S} p<0.05$ vs. women (Mann-Whitney ranks sum test).

Table 2. Subject characteristics and metabolic parameters in the four categories classified based on the sex and cardiorespiratory fitness level in all subjects.

\begin{tabular}{|c|c|c|c|c|c|c|c|}
\hline & \multicolumn{2}{|c|}{ Women } & \multicolumn{2}{|c|}{ Men } & \multicolumn{3}{|c|}{ Two-way ANOVA } \\
\hline & $\begin{array}{c}\text { Low-CRF } \\
(n=55)\end{array}$ & $\begin{array}{l}\text { High-CRF } \\
(n=22)\end{array}$ & $\begin{array}{c}\text { Low-CRF } \\
(n=60)\end{array}$ & $\begin{array}{l}\text { High-CRF } \\
(n=27)\end{array}$ & Interaction & Sex & $\begin{array}{l}\text { CRF } \\
\text { level }\end{array}$ \\
\hline Age (y) & $52.1 \pm 12.7$ & $50.5 \pm 10.8$ & $53.5 \pm 12.1$ & $45.7 \pm 12.2$ & & & $p=0.025$ \\
\hline BW (kg) & $55.4 \pm 8.7$ & $53.5 \pm 6.1$ & $73.3 \pm 10.5$ & $68.6 \pm 8.7$ & & $p<0.001$ & $p=0.035$ \\
\hline BMI $\left(\mathrm{kg} / \mathrm{m}^{2}\right)$ & $22.6 \pm 3.4$ & $21.4 \pm 1.9$ & $25.4 \pm 3.0$ & $23.3 \pm 2.5$ & & $p<0.001$ & $p=0.002$ \\
\hline $\mathrm{FM}(\mathrm{kg})$ & $17.7 \pm 5.9$ & $14.8 \pm 3.0$ & $17.7 \pm 5.4$ & $13.6 \pm 4.2$ & & & $p<0.001$ \\
\hline FFM $(\mathrm{kg})$ & $37.6 \pm 3.6$ & $38.7 \pm 4.0$ & $55.6 \pm 6.0$ & $54.9 \pm 5.0$ & & $p<0.001$ & \\
\hline $\mathrm{WC}(\mathrm{cm})$ & $81.1 \pm 10.0$ & $74.8 \pm 6.4$ & $89.4 \pm 7.2$ & $82.6 \pm 6.1$ & & $p<0.001$ & $p<0.001$ \\
\hline $\mathrm{AF}\left(\mathrm{cm}^{2}\right)$ & $241 \pm 103$ & $161 \pm 50$ & $295 \pm 91$ & $195 \pm 67$ & & $p=0.004$ & $p<0.001$ \\
\hline $\mathrm{VF}\left(\mathrm{cm}^{2}\right)$ & $74 \pm 40$ & $51 \pm 24^{\mathrm{a}}$ & $133 \pm 41^{b}$ & $83 \pm 34^{a, b}$ & $p=0.044$ & & \\
\hline $\mathrm{SF}\left(\mathrm{cm}^{2}\right)$ & $167 \pm 73$ & $111 \pm 37$ & $162 \pm 67$ & $112 \pm 47$ & & & $p<0.001$ \\
\hline$\dot{\mathrm{V}} \mathrm{O}_{2 \max }(\mathrm{mL} / \mathrm{kg} \mathrm{BW} / \mathrm{min})$ & $26.2 \pm 3.2$ & $35.3 \pm 4.1$ & $29.4 \pm 4.2$ & $40.0 \pm 4.2$ & & $p<0.001$ & $p<0.001$ \\
\hline$(\mathrm{mL} / \mathrm{kg}$ FFM/min $)$ & $38.5 \pm 4.9$ & $48.8 \pm 6.5$ & $38.5 \pm 5.2$ & $49.8 \pm 5.2$ & & & $p<0.001$ \\
\hline Fasting glucose $(\mathrm{mg} / \mathrm{dL})$ & $94 \pm 11$ & $91 \pm 8$ & $99 \pm 16$ & $96 \pm 11$ & & $p=0.027$ & \\
\hline $\mathrm{HbA}_{1 \mathrm{c}}(\%)$ & $5.15 \pm 0.38$ & $5.14 \pm 0.25$ & $5.19 \pm 0.78$ & $4.85 \pm 0.28$ & & & \\
\hline Fasting insulin $(\mu \mathrm{U} / \mathrm{mL})$ & $6.24 \pm 2.85$ & $5.76 \pm 2.59$ & $7.23 \pm 4.09$ & $5.26 \pm 2.02$ & & & $p=0.028$ \\
\hline HOMA-R & $1.45 \pm 0.71$ & $1.30 \pm 0.62$ & $1.76 \pm 1.00$ & $1.25 \pm 0.51$ & & & $p=0.015$ \\
\hline Adiponectin $(\mu \mathrm{g} / \mathrm{mL})$ & $10.8 \pm 4.6$ & $14.3 \pm 5.4^{\mathrm{a}}$ & $7.8 \pm 4.0^{\mathrm{b}}$ & $8.3 \pm 3.9^{b}$ & $p=0.043$ & & \\
\hline
\end{tabular}

Values are means \pm SD. CRF: cardiorespiratory fitness, BW: body weight, BMI: body mass index, FM: fat mass, FFM: fat-free mass, WC: waist circumference, $\mathrm{AF}$ : abdominal fat area $(\mathrm{AF}=\mathrm{VF}+\mathrm{SF})$, VF: visceral fat area, SF: subcutaneous fat area, $\mathrm{HbA}_{1 \mathrm{c}}$ : glycosylated hemoglobin, HOMA-R: homeostasis model assessment of insulin resistance $=($ fasting glucose $) \times($ fasting insulin)/405. Significance was determined by two-way ANOVA. ${ }^{a} p<0.05$ vs. low-CRF group (within the same sex group), ${ }^{\mathrm{b}} p<0.05$ vs. women (within the same CRF level).

Table 2 presents the comparison of characteristics and metabolic parameters in the four groups classified by sex and CRF. WC, AF, VF, and SF were significantly lower in the high-CRF group than in the low-CRF group in both men and women. Fasting insulin concentration and HOMA-R were significantly lower in the high-CRF than in the low-CRF group. Within the same CRF group, plasma adiponectin concentration was significantly higher in women.

WC and AF were highly correlated with HOMA-R $(r=0.457-0.585, p<0.001$, respectively) (Fig. 1A and B). The slopes and intercepts of the two regression lines 
A

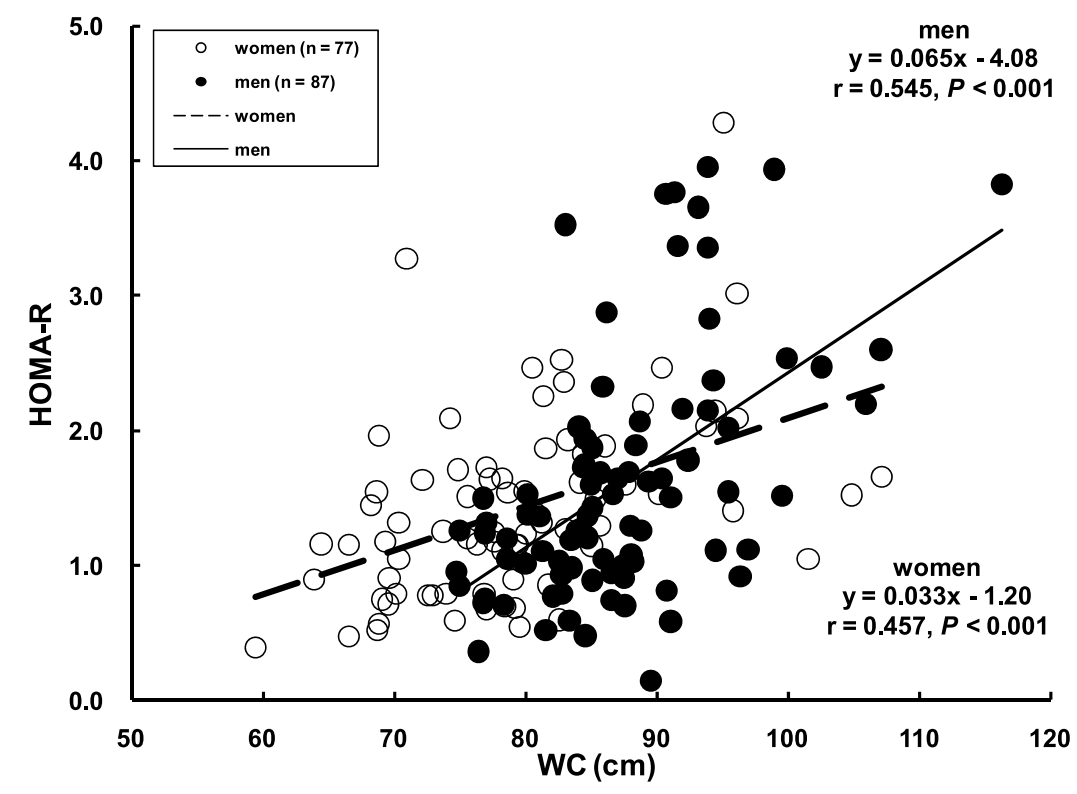

B

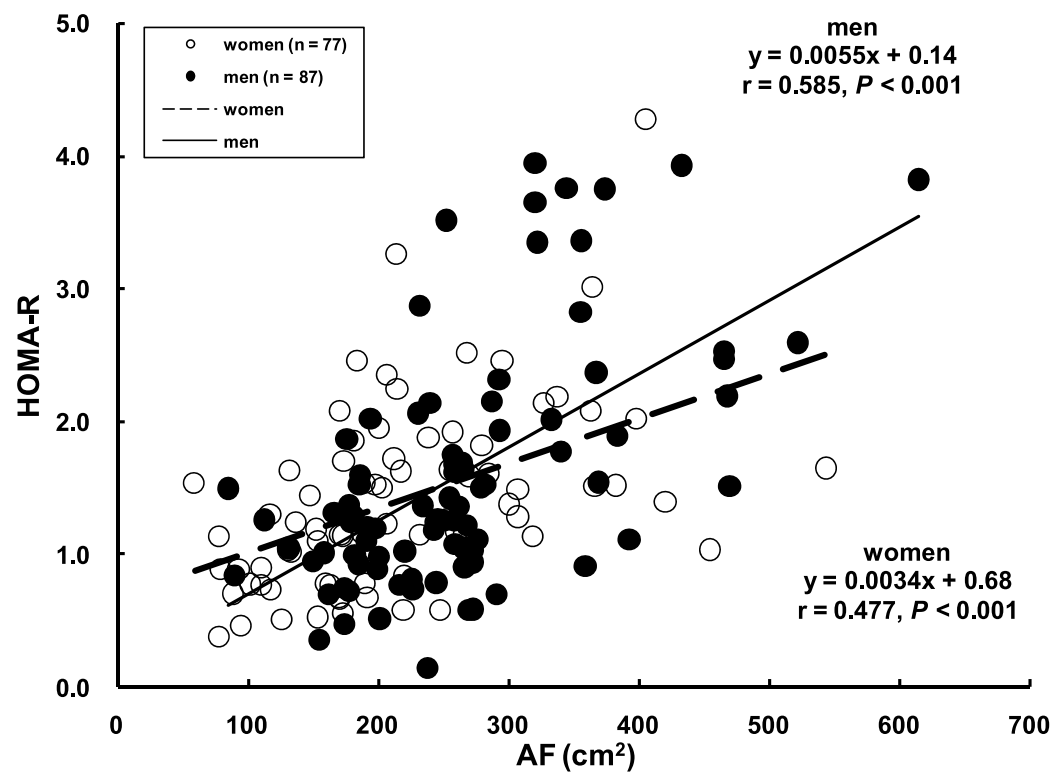

Fig. 1. Relationship between HOMA-R and waist circumference (A) or abdominal fat area (B). WC: waist circumference, $\mathrm{AF}$ : abdominal fat area $(\mathrm{AF}=$ visceral fat area+subcutaneous fat area).

of the relationship between WC and HOMA-R differed significantly between men and women (slopes, $t=2.476, p<0.05$; intercept, $t=2.622, p<0.01)$. VF and SF also correlated significantly with HOMA-R $(r=0.388-0.522, p<0.001)$ (Fig. $2 \mathrm{~A}$ and B). In contrast to the relationship between WC and HOMA-R (Fig. 1A), the associations between HOMA-R and AF, VF, or SF did not differ significantly between men and women (AF: slope, $t=1.956$; intercept, $t=1.850$; VF: slope, $t=0.165$; intercept, $t=1.257$; SF: slope, $t=1.909$; intercept, $t=0.949$ ) (Fig. 1B and Fig. 2A and B).

The relative importance of abdominal adiposity and CRF became more evident after the stepwise multiple linear regression analysis. After entering sex, age, VF,
SF, and $\dot{\mathrm{V}} \mathrm{O}_{2 \text { max }}$ into the model, only VF and SF explained a significant portion of HOMA-R $(24.2 \%$ and $6.4 \%$, respectively) (Table 3).

\section{DISCUSSION}

The previous studies indicated that abdominal fat and CRF are significant predictors of insulin resistance in adults including patients with IGT and diabetes $(6$, 7). However, it is not completely clear whether abdominal fat accumulation or low CRF is related to insulin resistance in non-diabetic people. With respect to patients with IGT and type 2 diabetes, Nagano et al. (7) recently used multivariate logistic regression analysis to assess the odds ratios for the prevalence of hyperin- 
A

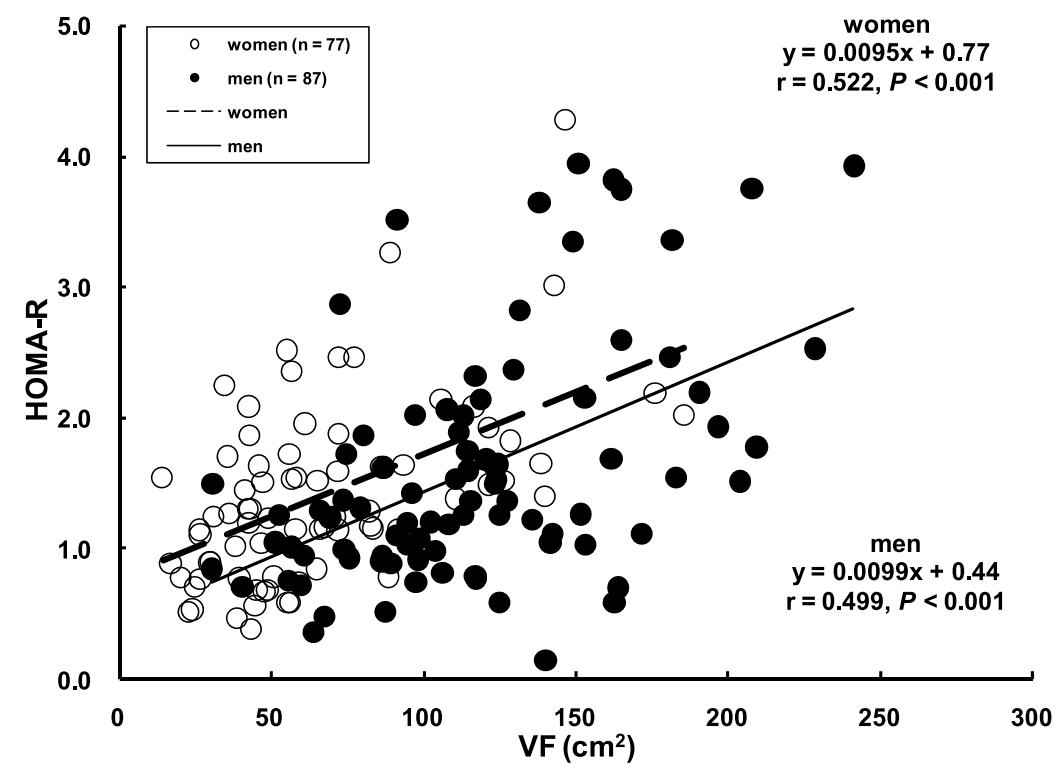

B

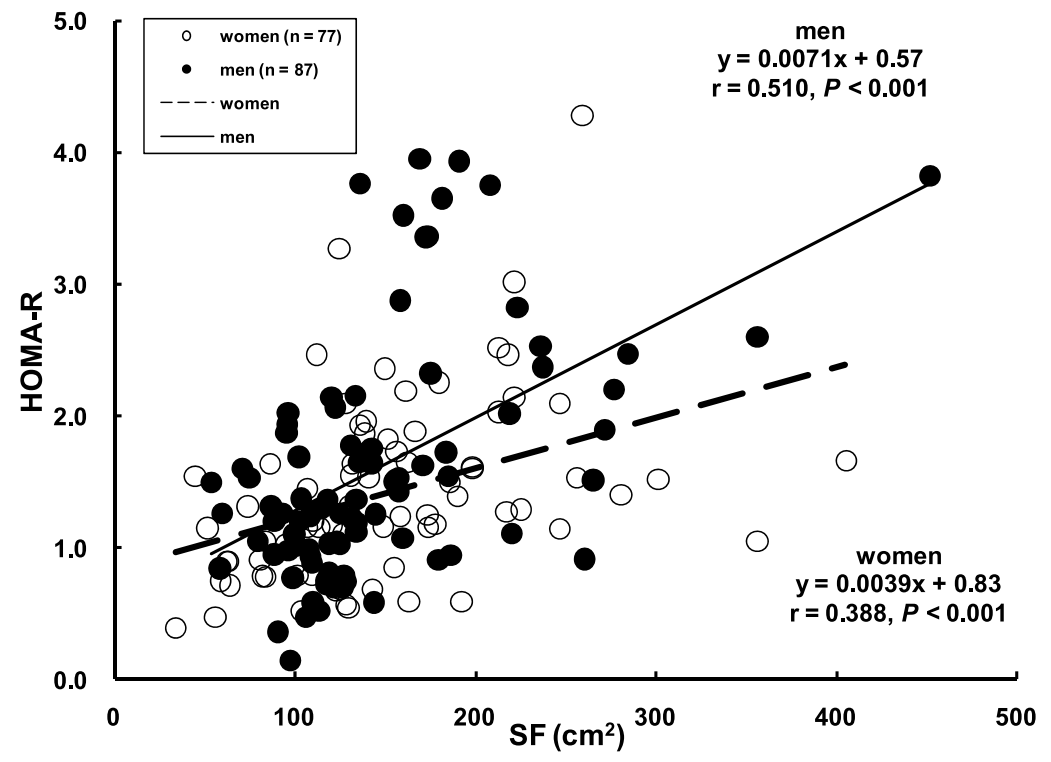

Fig. 2. Relationship between HOMA-R and visceral fat area (A) or subcutaneous fat area (B). VF: visceral fat area, SF: subcutaneous fat area.

sulinemia in three categories classified based on $\dot{\mathrm{V}} \mathrm{O}_{2 \max }$ adjusted for age and VF. A moderate and high CRF was significantly associated with a low prevalence of hyperinsulinemia compared with a low CRF. In the present study, to include the age-related decline in CRF (9) in the analysis, we also divided the men and women into two groups according to the category of CRF using the reference values given in EPARQ2006 in Japan (8). In the non-diabetic subjects, fasting insulin concentration and HOMA-R were significantly lower in the high-CRF group than in the low-CRF group (Table 2). This finding appears to confirm the recent finding by Nagano et al. (7) and provides further evidence that low CRF might be a predictor of insulin resistance in both non-diabetic individuals and patients with IGT and type 2 diabetes.
This suggests that increasing CRF may be a beneficial and effective treatment for preventing insulin resistance. However, as indicated in the stepwise multiple linear regression analysis, CRF was not a significant independent predictor of insulin resistance (Table 3). Unlike in patients with IGT and type 2 diabetes, in nondiabetic people, low CRF does not appear to be a direct and primary cause of insulin resistance.

On the other hand, previous studies have showed that $\mathrm{WC}$, an estimate of abdominal adiposity, was the most important predictor of insulin resistance in adults $(6,10)$. Similarly, as shown in Fig. 1A, WC was highly correlated with HOMA-R in the non-diabetic subjects. However, the relationship between WC and HOMA-R, differed between sexes because the regression line had a 
steeper slope in men (slopes, $t=2.476, p<0.05$ ). These findings suggested that the men are more prone than women to insulin resistance with even a slight increase in WC. In agreement with our results, Racette et al. (6) reported that men were more insulin resistant than women, despite being matched on age and BMI. These phenomena may be attributable to the difference in the distribution of VF and SF deposits between men and women. However, WC can not distinguish abdominal VF from SF, although WC is commonly used as a measure of central obesity in many epidemiological studies. Thus, we used MRI to assess the relative contributions of AF, which we divided into VF and SF, to HOMA-R. VF and SF correlated closely with HOMA-R in both sexes (Fig. 2A and B) and were both significant independent predictors of HOMA-R, explaining $24.2 \%$ and $6.4 \%$ of the variance, respectively. Sex, age, and CRF were not significant independent determinants (Table 3). In addi-

Table 3. Independent predictors of HOMA-R from multiple stepwise linear regression analysis.

\begin{tabular}{lrr}
\hline & $r^{2}$ & \multicolumn{1}{c}{$p$} \\
\hline HOMA-R & & \\
VF & 0.242 & $<0.001$ \\
SF & 0.064 & $<0.001$ \\
Age & & 0.063 \\
$\dot{V O}_{2 \text { max }}$ & & 0.148 \\
Sex & & 0.258 \\
Total $r^{2}$ & 0.306 & \\
\hline
\end{tabular}

Dependent variables: HOMA-R. Independent variables: sex, age, $\dot{V}_{2 \max }(\mathrm{mL} / \mathrm{kg} \mathrm{BW} / \mathrm{min}), \mathrm{VF}$, and SF. Sex, age, and $\dot{V}_{O_{2}}$ max were not retained in the model because they were not significant predictors. Values in the table represent the independent contributions to $r^{2}$ for each predictor variable in the model. VF: visceral fat area, SF: subcutaneous fat area. tion, the relationship between HOMA-R and VF or SF did not differ significantly between sexes (Fig. 2A and B). Similarly, Taniguchi et al. (11) demonstrated that insulin resistance was independently predicted by the VF and SF, whereas sex and age were not significantly associated with insulin resistance in non-obese Japanese patients with type 2 diabetes. Considering previous reports and our results, men and women with similar amounts of VF or SF in the abdomen do not exhibit sex differences in markers of insulin resistance. These data suggest that both VF and SF deposits should be important targets for the prevention of insulin resistance regardless of sex in non-diabetic people.

The precise mechanisms by which excess accumulation of visceral and subcutaneous adipose tissue leads to insulin resistance remain to be elucidated. Recent evidence indicates that adipose tissue is an active endocrine organ that releases several molecules with hormonal and proinflammatory actions (12-14). Adiponectin, an adipocytokine secreted from adipocytes, influences insulin action $(13,15)$. Consistent with previous studies $(16,17)$, we found that the plasma adiponectin concentration was more inversely correlated with VF accumulation $(r=-0.479, p<0.001)$ than with SF accumulation $(r=-0.289, p<0.001)$. Plasma adiponectin concentration was also closely associated with HOMA-R (Fig. 3). Yamauchi and colleagues (18, 19), and Kadowaki and colleagues (20) investigated the chronic effects of adiponectin on insulin resistance in vivo by generating adiponectin transgenic mice, and showed that adiponectin improved insulin resistance by decreasing triglyceride content in the liver. The weight loss intervention study by Lin et al. (17) showed that increasing the plasma concentration of adiponectin is associated with improved hepatic but not peripheral insulin sensitivity. HOMA-R is thought to assess mainly insulin resistance in the liver, because HOMA-R assesses the feedback loop between the liver and $\beta$-cells

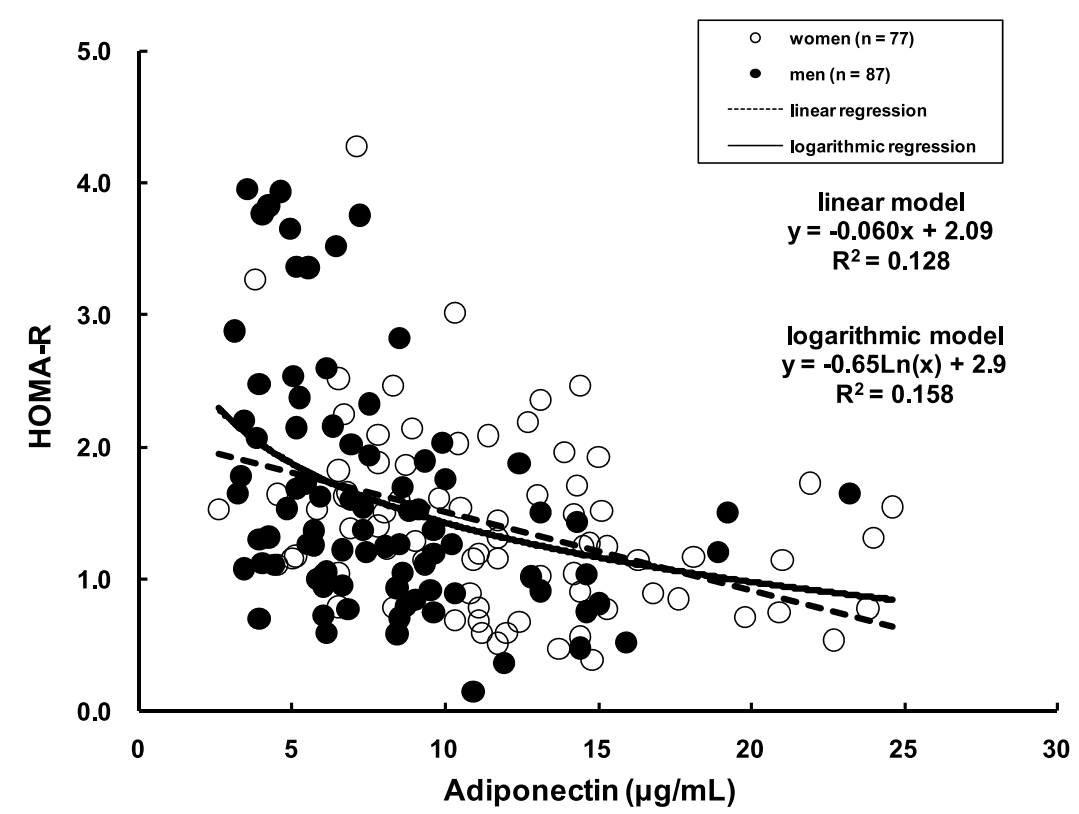

Fig. 3. Relationship between plasma adiponectin concentration and HOMA-R. 
in the steady state (21). Taken together, this evidence suggests that an improved HOMA-R occurs, at least in part, via an adiponectin-dependent mechanism and that increasing the secretion of adiponectin by reducing VF accumulation may be a promising way to improve and prevent insulin resistance, especially in the liver.

Our study has some limitations. As mentioned above, HOMA-R reflects insulin resistance in the liver rather than in fat and muscle (21), and is a relatively indirect method of measuring insulin resistance compared with the oral glucose tolerance test (OGTT) and euglycemic insulin clamp test. Further prospective and intervention studies are needed to assess whether reducing abdominal fat and increasing CRF influence glucose metabolic function in the whole body, as estimated by the OGTT and euglycemic insulin clamp test.

In conclusion, our data suggest that both visceral and subcutaneous fat in the abdomen are significant predictors of insulin resistance in non-diabetic people in both men and women and independently of CRF. VF seems to be the most important factor. Our results support the position that preventing $\mathrm{AF}$ deposition rather than increasing the level of CRF may be a more effective direct strategy for the primary prevention of type 2 diabetes in non-diabetic people.

\section{Acknowledgments}

The authors wish to express their appreciation to the subjects for their cooperation in this study. We thank Dr. Shin Terada for his contribution to the study. This work was supported by a Research Grant for Health Sciences Research Grants from the Ministry of Health, Labor and Welfare, Medical Health Care Research Grants from the Consolidated Research Institute for Advanced Science and Medical Care at Waseda University, and Academic Frontier Projects from the Ministry of Education, Culture, Sports, Science and Technology (05F-02).

\section{REFERENCES}

1) Lee ET, Keen H, Bennett PH, Fuller JH, Lu M, WHO Multinational Study Group. 2001. Follow-up of the WHO multinational study of vascular disease in diabetes: general description and morbidity. Diabetologia 44 (Suppl 2): S3-S13.

2) Ohmura T, Ueda K, Kiyohara Y, Kato I, Iwamoto H, Nakayama K, Nomiyama K, Ohmori S, Yoshitake T, Shinkawa A, Hasuo Y, Fujishima M. 1994. The association of the insulin resistance syndrome with impaired glucose tolerance and NIDDM in the Japanese general population: the Hisayama study. Diabetologia 37: 897904.

3) Qiao Q, Nakagami T, Tuomilehto J, Borch-Johnsen K, Balkau B, Iwamoto Y, Tajima N; International Diabetes Epidemiology Group; DECODA Study Group. 2000. Comparison of the fasting and the 2-h glucose criteria for diabetes in different Asian cohorts. Diabetologia 43: 1470-1475.

4) Tripathy D, Carlsson M, Almgren P, Isomaa B, Taskinen MR, Tuomi T, Groop LC. 2000. Insulin secretion and insulin sensitivity in relation to glucose tolerance: lessons from the Botnia Study. Diabetes 49: 975-980.
5) DeFronzo RA. 1992. Pathogenesis of type 2 (non-insulin dependent) diabetes mellitus: a balanced overview. Diabetologia 35: 389-397.

6) Racette SB, Evans EM, Weiss EP, Hagberg JM, Holloszy JO. 2006. Abdominal adiposity is a stronger predictor of insulin resistance than fitness among 50-95 year olds. Diabetes Care 29: 673-678.

7) Nagano M, Kai Y, Zou B, Hatayama T, Suwa M, Sasaki H, Kumagai S. 2004. The contribution of cardiorespiratory fitness and visceral fat to risk factors in Japanese patients with impaired glucose tolerance and type 2 diabetes mellitus. Metabolism 53: 644-649.

8) Ministry of Health, Labour and Welfare of Japan. 2006. Exercise and Physical Activity Reference Quantity for Health Promotion 2006 (EPARQ2006)-Physical Activity, Exercise, and Physical Fitness. General Affairs Division, Health Service Bureau, Ministry of Health, Labour and Welfare of Japan, Tokyo (in Japanese).

9) Pollock ML, Foster C, Knapp D, Rod JL, Schmidt DH. 1987. Effect of age and training on aerobic capacity and body composition of master athletes. J Appl Physiol 62: 725-731.

10) Kohrt WM, Kirwan JP, Staten MA, Bourey RE, King DS, Holloszy JO. 1993. Insulin resistance in aging is related to abdominal obesity. Diabetes 42: 273-281.

11) Taniguchi A, Nakai Y, Sakai M, Yoshii S, Hamanaka D, Hatae Y, Kawata M, Yamanouchi K, Okumura T, Doi K, Tokuyama K, Nagasaka S, Fukushima M. 2002. Relationship of regional adiposity to insulin resistance and serum triglyceride levels in nonobese Japanese type 2 diabetic patients. Metabolism 51: 544-548.

12) Maeda K, Okubo K, Shimomura I, Mizuno K, Matsuzawa Y, Matsubara K. 1997. Analysis of an expression profile of genes in the human adipose tissue. Gene 190: 227-235.

13) Ronti R, Lupattelli G, Mannarino E. 2006. The endocrine function of adipose tissue: an update. Clin Endocrinol (Oxf) 64: 355-365.

14) Hu E, Liang P, Spiegelman BM. 1996. AdipoQ is a novel adipose-specific gene dysregulated in obesity. $\mathrm{J}$ Biol Chem 271: 10697-10703.

15) Yamauchi T, Kamon J, Minokoshi Y, Ito Y, Waki H, Uchida S, Yamashita S, Noda M, Kita S, Ueki K, Eto K, Akanuma Y, Froguel P, Foufelle F, Ferre P, Carling D, Kimura S, Nagai R, Kahn BB, Kadowaki T. 2002. Adiponectin stimulates glucose utilization and fatty-acid oxidation by activating AMP-activated protein kinase. Nat Med 8: 1288-1295.

16) Motoshima H, Wu X, Sinha MK, Hardy VE, Rosato EL, Barbot DJ, Rosato FE, Goldstein BJ. 2002. Differential regulation of adiponectin secretion from cultured human omental and subcutaneous adipocytes: effects of insulin and rosiglitazone. J Clin Endocrinol Metab 87: 5662-5667.

17) Lin E, Phillips LS, Ziegler TR, Schmotzer B, Wu K, Gu LH, Khaitan L, Lynch SA, Torres WE, Smith CD, GletsuMiller N. 2007. Increases in adiponectin predict improved liver, but not peripheral, insulin sensitivity in severely obese women during weight loss. Diabetes 56: 735-742.

18) Yamauchi T, Kamon J, Waki H, Terauchi Y, Kubota N, Hara K, Mori Y, Ide T, Murakami K, TsuboyamaKasaoka N, Ezaki O, Akanuma Y, Gavrilova O, Vinson C, Reitman ML, Kagechika H, Shudo K, Yoda M, Nakano Y, Tobe K, Nagai R, Kimura S, Tomita M, Froguel P, Kado- 
waki T. 2001. The fat-derived hormone adiponectin reverses insulin resistance associated with both lipoatrophy and obesity. Nat Med 7: 941-946.

19) Yamauchi T, Kamon J, Waki H, Imai Y, Shimozawa N, Hioki K, Uchida S, Ito Y, Takakuwa K, Matsui J, Takata M, Eto K, Terauchi Y, Komeda K, Tsunoda M, Murakami K, Ohnishi Y, Naitoh T, Yamamura K, Ueyama Y, Froguel P, Kimura S, Nagai R, Kadowaki T. 2003. Globular adiponectin protected ob/ob mice from diabetes and ApoEdeficient mice from atherosclerosis. I Biol Chem 278:
2461-2468.

20) Kadowaki T, Yamauchi T, Kubota N, Hara K, Ueki K, Tobe K. 2006. Adiponectin and adiponectin receptors in insulin resistance, diabetes, and the metabolic syndrome. J Clin Invest 116: 1784-1792.

21) Matthews DR, Hosker JP, Rudenski AS, Naylor BA, Treacher DF, Turner RC. 1985. Homeostasis model assessment: insulin resistance and beta-cell function from fasting plasma glucose and insulin concentrations in man. Diabetologia 28: 412-419. 